\title{
EVALUATION OF BARRIERS FOR SIX SIGMA IMPLEMENTATION IN INDIAN MANUFACTURING SMES
}

Dharmendra Tyagi, V. K. Soni \&V. K. Khare

Department of Mechanical Engineering, Maulana Azad National Institute of Technology, Bhopal, Madhya Pradesh, India

ABSTRACT
This research paper is to evaluate and present the results from the online survey conducted in various Indian
manufacturing small and medium enterprises, mainly to focus barriers for implementing Six Sigma in Indian
manufacturing small and medium enterprises, and identified most critical barriers for Six Sigma implementation in
SMEs of manufacturing sector in India. The paper is based on survey questionnaire apposite for Indian manufacturing
small and medium enterprises and the result investigation of the present study is based on factor analysis and descriptive
statistics. The results are investigated by the factor analysis and reveal the impact of different barriers on the Indian
manufacturing small and medium enterprises.
KEYWORDS: Six Sigma, Barriers, Indian Manufacturing SMEs \& Factor Analysis

Received: May 03, 2017; Accepted: Jun 01, 2017; Published: Jun 13, 2017; Paper Id.: IJMPERDJUN201732

\section{INTRODUCTION}

All the enterprises need to improve their manufacturing processes in order to remain competitive in the market. These improvements can be achieved by increasing customer satisfaction, eliminating defects, improve product quality and enhance productivity (Nabeel, M. et al., 2012). Six Sigma has become one of the most popular tools to satisfy large enterprises need. However, its application in SMEs is still at the infancy stage. Six Sigma approach originated at Motorola in the early 1980s to reduce manufacturing defects. Hence, after successful implementation of Six Sigma in Motorola, various other enterprises generated attention in Six Sigma (Breyfogle, F. W., 2003), and it has an extension of total quality management (Green, F. B., 2006). Definition of Six Sigma is given by several researchers all over the world in different ways (Tomkins, R., 1997, Harry, M. J., 1998 \& Knowles, G., 2012), one of the aims is to remove inefficiency and waste, thereby customer satisfaction by delivering what the customer is expecting.

The word Sigma is a statistical term that measures how far a given process deviates from perfection. Six Sigma has been widely adopted by American businesses because it works! Six Sigma is a problem solving methodology that reduces costs and improves customer satisfaction by greatly reducing waste in all the processes involved in the creation and delivery of your products and/or services. The central approach behind Six Sigma is that if you can determine how many "defects" in a process, you can riddle out systematically how to diminish them and get as close to "zero defects" as possible and specifically it means a failure rate of 3.4 defects per million opportunities or $99.9997 \%$ perfect. Six Sigma quality level is like parking a small motor vehicle in a relatively big area (Dedhia, N. S., 2005). 
Six Sigma approach has started initially from the electronic industries to other sectors and growing continuously in different branches. Six Sigma have also been implemented and playing very important role in process, service industries (Prabhakar, K. et al., 2009 \& Chakrabarty, A. et al., 2009), health care industries (Mehmet, T. T. et al., 2009 \& Julie, E. at el., 2009), automobile industries (Sokovic, M. et al., 2006 \& Adan, V. et al., 2009) as well as food distribution industries (Farhad, N. et al., 2009). In the past recent years, Six Sigma has also been moved towards small medium enterprises (SME) which must adopt Six Sigma to remain competitive in the market but SMEs may have many reservations regarding Six Sigma implementation. The present study are an attempt to analyze barriers of Six Sigma implementation in Indian manufacturing SMEs and identify critical barriers for Six Sigma implementation in SMEs of manufacturing sector in India.

\section{REVIEW OF LITERATURE}

\section{Six Sigma Moves Toward SMEs}

Earlier, discussed about Six Sigma origin and definitions but in depth stepwise discussion on Six Sigma philosophy from origin to SMEs was needed for research view point. Six Sigma philosophy originated at Motorola in 1980's when company decided to make defect free manufacturing processes. Positive outcomes came after implementation of Six Sigma in Motorola then GE adopted it in mid 1990s. Six Sigma approach has become one of the most popular techniques implemented in different sectors around the world such as companies named Toshiba, Sony, Allied signal, Texas instruments, Boeing, Honeywell, Kodak and many others implemented Six Sigma and gained huge amount of savings by the implementation of Six Sigma (Knowles, G., 2012).

Six Sigma approach also concentrated on business quality to produce product on zero defect rate by minimum cost of production at maximum profit. Some other benefits have seen from Six Sigma include improved design, shorter cycle time, increased customer satisfaction. Six Sigma approach became a synonym for reducing cost, improving quality, improving customer satisfaction, improving processes, reducing defects and reducing process variability.

Six Sigma is based on various quality management theories (e.g.: Deming's 14 point for management, Juran's 10 steps on achieving quality) and initially implemented in manufacturing processes and later product, service, purchasing, billing, marketing were also involved. Evolution of Six Sigma is continuing by adopting it as managerial approach to change culture of the organizations in different ways. It was a statistical approach or use of statics in Six Sigma projects. All processes consists deviations, Six Sigma aims to reduce deviations using statics for project success. It was also be presented as a break through strategy because DMAIC process as break through or step by step target achieving methodology (Snee, R. D., 2003).

Six Sigma methodologies implemented to improve effectiveness of service organizations and delivery of products. It is a problem solving methodology that enhances customer satisfaction by reducing waste in all the processes, product and services. Competition for profit or saving has become growing in every day and small medium enterprises are trying to remain competitive in the market by producing more cost efficient products with the implementation of Six Sigma in it because Six Sigma approach can help to improve effectiveness of small medium enterprises to a larger extent.

\section{SMEs Sector in India}

According to the act passed by the Government of India in October 2006, Micro, Small and Medium Enterprises (MSMEs) are classified as under (Deshmukh, S. V. et al., 2012 \& Singh, M. D. et al., 2015). 
Table 1: Classification of Enterprises in to Different Categories (Effective from 02 October 2006)

\begin{tabular}{|l|l|l|}
\hline \multirow{2}{*}{ Enterprises } & \multicolumn{2}{|c|}{ Investment in Plant and Machinery } \\
\cline { 2 - 3 } & \multicolumn{1}{|c|}{ Manufacturing } & \multicolumn{1}{c|}{ Service } \\
\hline Micro & Up to Rs 25 lakhs & Up to Rs 10 lakhs \\
\hline Small & Between 25 lakhs to Rs 5 crores & Between 10 lakhs to Rs 2 crores \\
\hline Medium & Between Rs 5 crores to 10 crores & Between Rs 2 crores to 5 crores \\
\hline
\end{tabular}

\section{Barriers for Implementing Six Sigma by SMEs}

Six Sigma techniques, since its origin, have been generally concerned with large organizations. Growing medium sized enterprises have also benefited from Six Sigma program. They are getting enormous amount of savings and satisfactory growth from implementation of Six Sigma program. However, its application is less evident in the literatures in small medium enterprises due to many barriers for implementing Six Sigma by SMEs include lack of knowledge of the system to take initiative for improvement, lack of resources, cost issues, lack of guidance from executives cultural change, poor selection of projects and low training from high level executives (Raghunath, A. et al., 2013).

From the survey in UK small medium enterprises (Kumar, M. et al., 2009) showed that lack of resources was key barrier to implementation of Six Sigma in SMEs followed by others such as lack of knowledge and training, internal resistance, poor participation of employee, lack of executive commitment etc. also played very important role in Six Sigma implementation by SMEs (Kumar, M. et al., 2005 \& Kumar, M. 2007).

One of the most important barriers was lack of knowledge (Kumar, M. et al., 2008) of Six Sigma implementation. The basic of Six Sigma strategy was developed by "Juran Tribology" used to achieve best quality results. Six Sigma helps organizations to reduce defects in all processes, product and services and focusing on the financial matter of an organization. Six Sigma projects need lot of expertise to run efficiently. Knowledge of Six Sigma and their methodology is very necessary for management people at different stages of an organization. Six Sigma can help to save huge amount of money if all the people having knowledge about it. All companies require cultural change in an organization for remain competitive in the market but employees of an organization may not be satisfied to change. These problems and issues arise within an organization should be handled by a good manager for successful implementation of initiative.

The greatest barrier to Six Sigma implementation in small medium enterprises has become lack of training and guiding for success of project, training of each employee should be started by company, but the cost of training program was too much higher for SMEs (Fouweather, T. et al., 2006 \& Kumar, M. et al., 2009). Now a day, it is very easier in SMEs to get better external resources for guidance without paying more cost.

\section{Methodologies Used for Implementing Six Sigma}

Researchers all over the world suggest two key methodologies for implementation of Six Sigma: DMAIC (Define, Measure, Analyze, Improve and Control) (Sahoo, A. K. et al., 2008, Erick, C. J. et al., 2010, Mast, J. et al., 2012 \& Chang, S. I. et al., 2012) and DFSS (Design for Six Sigma) (Ida, G., 2012), the main purpose of both methods are different. Initially, both methods were used for Six Sigma implementation and later on some modifications were exist such as DMADV (Define, Measure, Analyze, Design and Verify) and DCOV (Design, Characterize, Optimize and Verify) (Chakrabarty, A. et al., 2007, Arumugam, V. et al., 2016 \& Nedeliakova, E. et al., 2017). 


\section{RESEARCH OBJECTIVES AND METHODOLOGY}

The main fundamental objective of this research is to "analyze the barriers of Six Sigma within manufacturing Indian SMEs to which Six Sigma is being implemented" and this can be achieved by constructing many research questions systematically, the objective is further classified into various number of specific research questions as follows:

- $\quad$ To study of the status of Six Sigma implementation in manufacturing Indian SMEs.

- To study barriers of Six Sigma implementation in manufacturing Indian SMEs.

- To suggest most critical barriers for better implementation of Six Sigma in manufacturing Indian SMEs.

To achieve above objectives, a survey questionnaire was prepared with the help of literature. It was framed to provide a bottom line for Six Sigma practices by manufacturing SMEs in India. It consists of four parts:

- SMEs demographic information for survey.

- $\quad$ SMEs experience with implementation of Six Sigma.

- $\quad$ Barriers for implementation of Six Sigma in manufacturing Indian SMEs.

An online questionnaire survey of Indian manufacturing small and medium enterprises was conducted to understand the status of Six Sigma implementation. Also, this study can help to explore the barriers of Six Sigma implementation.

The list of organizations included for the survey refers to Indian 1500 manufacturing organizations list, which is identified on the basis of Six Sigma implementation. The questionnaire was mailed to 1500 respondents and requested them to read the questions and respond as early as possible. Responses were collected from 301 organizations within two month by taking three follow-ups and response rate was $20.06 \%$.

The questionnaire focused on barriers for Six Sigma implementation, as well as it included demographic information of organization. Barriers are measured by seven point likert type scale $(1=$ Not at all important, $7=$ Crucial $)$. The all contents of questionnaire were reviewed by the knowledgeable persons of Six Sigma implementation. This process helped to identify the suitable questions for organization.

\section{RESULTS AND DISCUSSIONS}

Demographic Information of SMEs

Data were collected from 301 organizations. Out of 301 organizations, 124 organizations were found to be small, while 177 organizations fulfilled the criteria of medium enterprises. As Figure 1 show that the type of small and medium sized organizations considered for this study. 


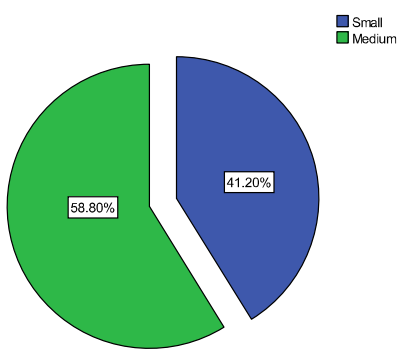

\section{Figure 1: Size Distribution of Auto Component Indian SMEs Where Six Sigma Tool is Operational}

The research findings revealed that the majority of the manufacturing Indian SMEs had a financial turnover of Rs $1-5$ crores (see figure 2). Further, around $90 \%$ of the manufacturing Indian SMEs have the annual financial turnover up to Rs 10 crores. These results focus towards the need to implement Six Sigma methodology that could result in increasing profit margins and enhancing the performance of manufacturing Indian SMEs (Kumar, M. et al., 2008).

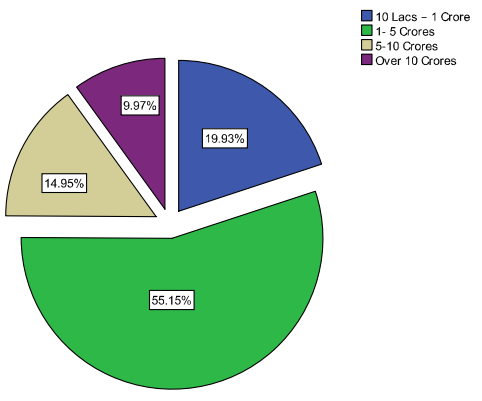

Figure 2: Annual Financial Auto Component Indian SMEs Turnover (Rs)

Further, the research findings showed that management was extensively shown their involvement in quality matters, as more than $50 \%$ of the respondents were a general manager/director/CEO. Quality is more important for SMEs than others, figure 3 showed that the current position of the respondents.

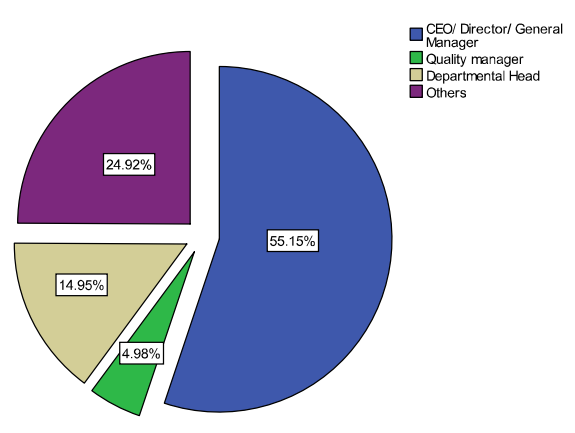

Figure 3: Profile of the Respondents

Customer focus is the top quality product with zero defects. Accordingly, respondents were asked to draw attention to show avenues used by them to concentrate on customer and to capture their response. A list of opinions was given them from which to choose and responses recorded in figure 4. The results reveal that all manufacturing Indian SMEs measured customer satisfaction. The majority (55 percent) of manufacturing Indian SMEs used "customer 
complaints", followed by "surveys" (40 percent) and "delivery times" (5 percent) to measure customer satisfactions (see figure 4). These results are similar to the findings in the Australia and UK SMEs. It showed that most of the companies trusted on customer complaints to receive the feedback of product. Customer complaint is immediate approach to measure customer satisfaction and usually it is customer initiated approach.

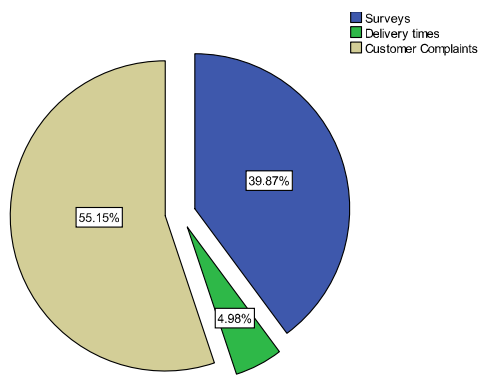

Figure 4: How Does Your Enterprise Measure the Customer Satisfaction?

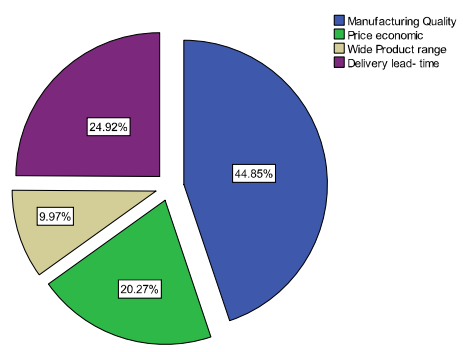

Figure 5: Important Criteria That Helped To Win Customer Loyalty

Further, to assess the purpose of manufacturing Indian SMEs targeting on their customers, the manufacturing Indian SMEs were asked to highlight the most important criteria that helped to win customer loyalty from a list. They ranked manufacturing quality highly, followed by delivery lead time, price economic and wide product range (see figure 5).

\section{Barriers Analysis}

To meet the objective of barriers of Six Sigma implementation in manufacturing Indian SMEs as whole, the respondents were asked to rank the barriers in a scale of 1 to 7 as mentioned above. Accordingly respondents have provided their rating of all barriers and then evaluated all barriers by running exploratory factor analysis.

Organizations were asked to highlight the most important factors that were felt to be barriers to implement Six Sigma initiatives in the manufacturing Indian SMEs. The results of the analysis revealed that most of the respondents declared that Lack of top mgmt commitment, lack of resources, Lack of knowledge and Lack of leadership from top executives (see table 4) are found most critical barriers to the successful implementation of Six Sigma initiatives in the manufacturing Indian SMEs.

Normality is a group of statistical tests that need data, that are normally distributed and therefore, we should always ensure, if this assumption is violated. Reliability is the measure of how accuracy the measurement is made (Lande, M. S. et al., 2016). While there is group of information to be gathered from appearing at correlations, what you actually 
desire in a single summery statistic that notifies us how reliable our surveys is. Cronbach's alpha is a measure of reliability. Coefficient of reliability should be 0.70 or higher is acceptable.

Table 2: Reliability Statistics

\begin{tabular}{|c|c|}
\hline Cronbach's Alpha & N of Items \\
\hline 923 & 22 \\
\hline
\end{tabular}

The Bartlett's Test of Sphericity tests the adequacy of the correlation matrix, and yielded a value of 4061.908 and an associated level of significance smaller than 0.001 (Robert, H., 2006). Thus, the hypothesis that the correlation matrix is an identity matrix can be rejected, i.e., the correlation matrix has significant correlations among at least some of the variables.

Table 3: KMO and Bartlett's Test

\begin{tabular}{|l|l|c|}
\hline \multicolumn{2}{|l|}{ Kaiser-Meyer-Olkin Measure of Sampling Adequacy. } & 898 \\
\hline \multirow{3}{*}{ Bartlett's Test of Sphericity } & Approx. Chi-Square & 4061.908 \\
\cline { 2 - 3 } & df & 231 \\
\cline { 2 - 3 } & Sig. & 000 \\
\hline
\end{tabular}

Factor analysis output gives an idea about the table of communalities (see table 4), before and after extraction. Principle component analysis works on the initial assumption that all variance is common; therefore all communalities are 1 before extraction. The communalities in the column labeled Extraction show the common variance in the data structure

Table 4: Communalities

\begin{tabular}{|l|c|c|}
\hline \multicolumn{1}{|c|}{ Barriers } & Initial & Extraction \\
\hline Lack of knowledge & 1.000 & 843 \\
\hline Lack of resources & 1.000 & 874 \\
\hline Lack of training & 1.000 & 629 \\
\hline Lack of education of value of Six Sigma & 1.000 & 631 \\
\hline Internal resistance & 1.000 & 533 \\
\hline Poor employee participation & 1.000 & 513 \\
\hline Insufficient interdepartmental communication & 1.000 & 746 \\
\hline Satisfaction with other quality programs & 1.000 & 768 \\
\hline Insufficient organizational alignment & 1.000 & 711 \\
\hline Poor project selection & 1.000 & 643 \\
\hline Insufficient time to work on Six Sigma projects & 1.000 & 680 \\
\hline Satisfaction with other quality programs & 1.000 & 613 \\
\hline Large investment in Six Sigma training & 1.000 & 731 \\
\hline Changing business focus & 1.000 & .640 \\
\hline Difficulty in identifying process parameters & 1.000 & .515 \\
\hline Inadequate process control techniques & 1.000 & .649 \\
\hline Misunderstanding of process and sub-processes & 1.000 & .620 \\
\hline Poor delegation of authority & 1.000 & .645 \\
\hline Insufficient financial resources & 1.000 & .722 \\
\hline Lack of top mgmt commitment & 1.000 & .879 \\
\hline Lack of leadership from top executives & 1.000 & .812 \\
\hline Poor supplier involvement & 1.000 & .658 \\
\hline Extraction Method: Principal Component Analysis. & \\
\hline
\end{tabular}

Scree test is used to identify the optimum number of factors that can be extracted before the amount of unique 
variance begins to dominate the common variance structure. Graphically, the plot has shown a steep slope between the large factors and the gradual trailing off of the rest of the factors. The point at which the curve first begins to straighten out is considered to indicate the maximum number of factors to extract (Robert, H., 2006).

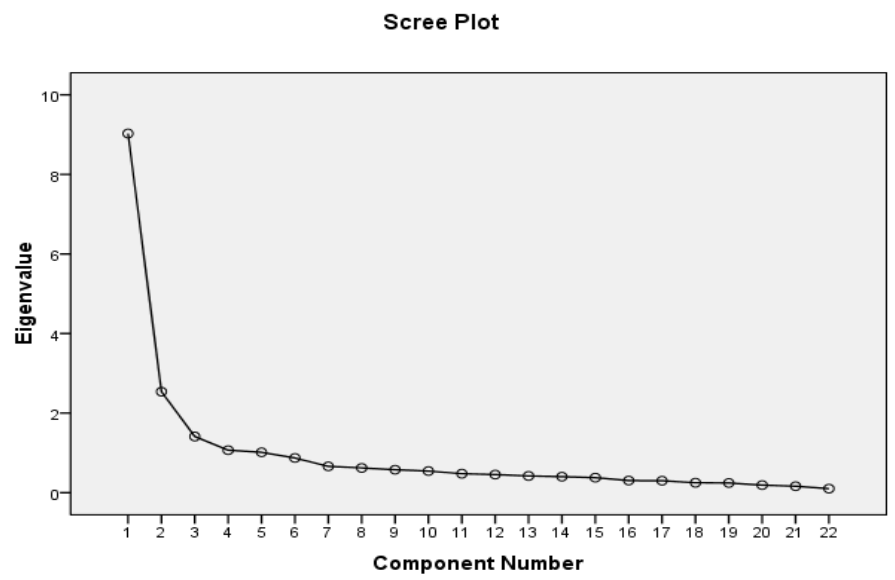

Figure 6: Scree Plot

Factor Analysis to reduce the data size and form the families of similar dimensions based on the Correlation Coefficient and their factor loadings. Analysis revealed that five factors extracted and Cronbach's alpha for each factor is shown in table 5 along with factor loadings. Value of Cronbach's alpha for each factor were found more than 0.80.

\section{Table 5: Technical Factors Extracted}

\begin{tabular}{|c|c|c|c|}
\hline Factor & Technical Factors & $\begin{array}{c}\text { Factor } \\
\text { Loadings }\end{array}$ & Proposed Factor label \\
\hline \multirow{5}{*}{ Factor 1} & Large investment in Six Sigma training & 816 & \multirow{5}{*}{$\begin{array}{l}\text { Lack of quality focus } \\
\left(C R O N B A C H^{\prime} S\right. \\
A L P H A=0.862)\end{array}$} \\
\hline & Satisfaction with other quality programs & 727 & \\
\hline & Poor project selection & 724 & \\
\hline & Changing business focus & 718 & \\
\hline & Insufficient time to work on Six Sigma projects & 620 & \\
\hline \multirow{5}{*}{ Factor 2} & Lack of supportive organizational culture & 833 & \multirow{5}{*}{$\begin{array}{l}\text { Lack of support and communication } \\
\left(C R O N B A C H^{\prime} S\right. \\
A L P H A=0.863)\end{array}$} \\
\hline & Insufficient interdepartmental communication & 786 & \\
\hline & Insufficient organizational alignment & 770 & \\
\hline & Poor employee participation & 656 & \\
\hline & Internal resistance & 586 & \\
\hline \multirow{5}{*}{ Factor 3} & Poor supplier involvement & 842 & \multirow{5}{*}{$\begin{array}{l}\text { Lack of process understanding } \\
\left(C R O N B A C H^{\prime} S\right. \\
A L P H A=0.820)\end{array}$} \\
\hline & Inadequate process control techniques & 774 & \\
\hline & Misunderstanding of process and sub-processes & 721 & \\
\hline & Poor delegation of authority & 688 & \\
\hline & Difficulty in identifying process parameters & 613 & \\
\hline \multirow{4}{*}{ Factor 4} & Lack of knowledge & 988 & \multirow{4}{*}{$\begin{array}{l}\text { Lack of resources and Knowledge } \\
\left(C R O N B A C H^{\prime} S\right. \\
A L P H A=0.858)\end{array}$} \\
\hline & Lack of resources & 897 & \\
\hline & Lack of training & 598 & \\
\hline & Lack of education of value of Six Sigma & 537 & \\
\hline \multirow{3}{*}{ Factor 5} & Lack of top mgmt commitment & 940 & \multirow{3}{*}{$\begin{array}{l}\text { Lack of leadership and Mgt. } \\
\text { Involvement } \\
\left(C R O N B A C H^{\prime} S A L P H A=0.865\right)\end{array}$} \\
\hline & Lack of leadership from top executives & 930 & \\
\hline & Insufficient financial resources & 724 & \\
\hline
\end{tabular}




\section{CONCLUSIONS}

For worldwide competitiveness, manufacturing Indian SMEs are motivated to accomplish overall enterprise performance in their business. Importance of Six Sigma is growing in manufacturing Indian SMEs, to satisfy the enterprises need. The study was aimed to find out the most critical barriers for Six Sigma implementation in manufacturing Indian SMEs. Analysis revealed that each factor is statistically significant in terms of importance and application of barriers within manufacturing Indian SMEs but four barriers (Lack of top mgmt commitment, lack of resources, Lack of knowledge and Lack of leadership from top executives) out of 22 were found most crucial.

It can be concluded that exploratory factor analysis has identified five factors from the list of 22 Barriers. These factors are represented by the specific statements written to reflect the proposed factors label. Reliability test in an EFA were computed Cronbach's alpha for each proposed factor and value of alpha were found above 0.80 , which indicates high overall internal correlation among the factors representing proposed factors label.

Manufacturing Indian SMEs have already implemented Six Sigma methodology as a breakthrough continuous improvement strategy for pleasing to the eye performance of SMEs. An extensive study regarding barriers of Six Sigma implementation in manufacturing Indian SMEs was required, since Six Sigma is receiving more importance among manufacturing Indian SMEs. This study can help other manufacturing Indian SMEs, who have yet not implemented Six Sigma methodology.

\section{REFERENCES}

1. Nabeel, M., Rami, H. F., \& Suleiman, O. (2012). An Application of Customized Lean Six Sigma to Enhance Productivity at a Paper Manufacturing Company. Jordan Journal of Mechanical and Industrial Engineering, 6, 103 - 109.

2. Breyfogle, F. W. (2003). Implementing Six Sigma (2nd ed.). NJ: John Wiley \& Sons, Hoboken.

3. Green, F. B. (2006). Six Sigma and the revival of TQM. Total Quality Management \& Business Excellence, 17, 1281-86.

4. Tomkins, R. (1997). GE beats expected 13\% rise. Financial Times, 22.

5. Harry, M. J. (1998). Six Sigma: a breakthrough strategy for profitability. Quality Progress, 60-4.

6. Knowles, G. (2012). Profit from Six Sigma: A Guide to Principles and Practice for Business Benefit. Ventus Publishing ApS.

7. Dedhia, N. S. (2005). Six sigma basics. Total Quality Management \& Business Excellence, 16, 567-574.

8. Prabhakar, K., \& Khanduja, D. (2009). Application of Six Sigma DMAIC methodology in thermal power plants: A case study. Total Quality Management \& Business Excellence, 20, 197-207.

9. Chakrabarty, A., \& Tan, K. C. (2009). An exploratory qualitative and quantitative analysis of Six Sigma in service organizations in Singapore. Management Research News, 32, 614-632.

10. Mehmet, T. T., \& Bulent, S. (2009). An application of Six Sigma methodology to turnover intentions in health care. International Journal of Health Care Quality Assurance, 22, 252-265.

11. Julie, E., Dorian, D., \& Terry, Y. (2009). An exploratory survey of current practice in the medical device industry. Journal of Manufacturing Technology Management, 20, 218-234.

12. Sokovic, M., Pavletic, D., \& Krulcic, E. (2006). Six Sigma process improvements in automotive parts production. Journal of Achievements in Materials and Manufacturing Engineering, 19, 96-102. 
13. Adan, V., Salvador, N., Jaime, S., Erwin, M., \& Jesus, S. (2009). Six Sigma Improvement Project for Automotive Speakers in an Assembly Process. International journal of industrial engineering, 16, $182-190$.

14. Farhad, N., \& Alireza, S. (2009). Reducing the delivery lead time in a food distribution SME through the implementation of six sigma methodology. Journal of Manufacturing Technology Management, 20, 957-974.

15. Snee, R. D., \& Hoerl, R. W. (2003). Leading Six Sigma - A Step by Step Guide Based on Experience with General Electric and Other Six Sigma Companies. New York: FT Prentice Hall.

16. Deshmukh, S. V., \& Chavan, A. (2012). Six Sigma and SMEs: a critical review of literature. International Journal of Lean Six Sigma, 3, $157-167$.

17. Singh, M. D., \& Thakur, G. D., \& Sharma, P. A (2015). Review of Six Sigma implementation Practices in Indian SMEs Particularly in State of Gujarat. Industrial Engineering Journal, 8, 15-21.

18. Raghunath, A., \& Jayathirtha, R. V. (2013). Barriers for implementation of Six Sigma by Small and Medium Enterprises. International Journal of Advancements in Research \& Technology, 2, 1-7.

19. Kumar, M., \& Antony, J. (2009). Multiple case-study analysis of quality management practices within UK Six Sigma and nonSix Sigma manufacturing small- and medium-sized enterprises. Journal of Engineering Manufacture, 233, 925-934.

20. Kumar, M., Antony, J., \& Christian, N. M. (2005). Six Sigma in small- and medium-sized UK manufacturing enterprises: Some empirical observations. International Journal of Quality \& Reliability Management, 22, 860 - 874.

21. Kumar, M. (2007). Critical success factors and hurdles to Six Sigma implementation: the case of a UK manufacturing SME. International Journal of Six Sigma and Competitive Advantage, 3, 333-51.

22. Kumar, M., \& Antony, J. (2008). Comparing the quality management practices in UK SMEs. Industrial Management \& Data Systems, 108, $1153-1166$.

23. Fouweather, T., Coleman, S., \& Thomas, A. (2006). Six sigma training programs to help SMEs improve. $2^{\text {nd }}$ Intelligent Production Machines and Systems Virtual International Conference, 39-44.

24. Kumar, M., Antony, J., \& Douglas, A. (2009). Does size matter for Six Sigma implementation? Findings from the survey in UK SMEs. The TQM Journal, 21, 623-635.

25. Sahoo, A. K., Tiwari, M. K., \& Mileham, A. R. (2008). Six Sigma based approach to optimize radial forging operation variables. Journal of materials processing technology, 202, 125-136.

26. Erick, C. J., Mahour, M. P., \& Stephanie, G. A. (2010). A framework for effective Six Sigma implementation. Total Quality Management \& Business Excellence, 21, 415 - 424.

27. Mast, J., \& Lokkerbol, J. (2012). An analysis of the Six Sigma DMAIC method from the perspective of problem solving. International Journal of Production Economics, 12, 1-29.

28. Chang, S. I., David, C. Y., Chou, C. C., Wu, H. C., \& Lee, H. P. (2012). Applying Six Sigma to the management and improvement of production planning procedure's performance. Total Quality Management \& Business Excellence, 23, 291 308.

29. Ida, G., \& Jean, B. F. (2012). Design for Six Sigma and lean product development. International Journal of Lean Six Sigma, 3, $45-58$.

30. Chakrabarty, A., \& Tan, K. C. (2007). The current state of Six Sigma application in services. Managing Service Quality, 17, 194-208. 
31. Arumugam, V., Antony, J., \& Linderman K. (2016). The influence of challenging goals and structured method on Six Sigma project performance: A mediate d moderation analysis. European Journal of Operational Research, 254, 202-213.

32. Nedeliakova, E., Stefancova, V. \& Kudlac, S. (2017). Six Sigma and Dynamic Models Application as an Important Quality Management Tool in Railway Companies. Procedia Engineering, 187, 242 - 248.

33. Lande, M. S., Shrivastava., R. L. (2016). Quality practice model for micro small medium enterprises (MSMEs). Industrial Engineering Journal, 9, 43-46.

34. Robert, H. (2006). Handbook of univariate and multivariate data analysis and interpretation with SPSS. New York: Chapman \& Hall/CRC. 
